\title{
The phenomenal determination of retroaction and proaction: III. Contextual vs. temporal organization of two lists
}

\author{
LEONARD BROSGOLE and JOHN J. GROSSO \\ St. John's University, Jamaica, New York 11439
}

\begin{abstract}
A study was run dealing with RI and PI in which subjects learned two stories, one about Christmas Eve and the other about New Year's Eve. Each story contained pairs, consisting of color names and CVC trigrams. The recall of the response items was assessed at delays of $20 \mathrm{~min}$ and $24 \mathrm{~h}$. One group learned the Christmas Eve story followed by the New Year's Eve story, and another group learned them in reverse order. While RI and PI effects were found in both groups, there was a significant reduction of RI for the second group, in which the contextual sequence of the stories conflicted with their temporal order. These findings suggested that RI and PI may result from the manner in which materials are organized in memory, as opposed to unlearning at the point of interpolated practice.
\end{abstract}

Brosgole (1976a) found evidence for retroactive interference (RI) and proactive interference (PI) in the learning of a single list of paired associates. Whereas response recall was superior to stimulus recall in shortterm memory, the recall of both members of the pairs equalized after a 24-h delay interval. This equalization was accomplished by a significant increment in stimulus recall, accompanied by a reliable decrement in the memory of the response items. It is as if the response items (which were perceived as coming after or following the stimulus members) initially interfered retroactively with the memory of the stimulus items, which then spontaneously recovered with the passage of time to compete on an equal footing with the recall of the responses (producing PI). In an additional study, Brosgole, Lederer, and Kozlowski (1976) showed that this effect was contingent upon the similarity between the stimulus and response members of the pairs. In yet another study, Brosgole and Duffy (1976) demonstrated RI and PI in the simultaneous acquisition of two serial lists.

In all of the above experiments, interference effects were found in simultaneous learning situations. Such findings ruled out an "unlearning" interpretation of retroaction, because there was no interpolated practice period during which the extinction of original learning could occur. In the absence of unlearning, proaction could not be explained in terms of the competition provided by the spontaneous recovery of the originally mastered materials. The net result of the above findings was to reject the two-factor interpretation of RI and PI, which relies so heavily upon the extinction and spontaneous recovery of original learning.

The authors express their appreciation to Peter G. Boettcher and Thomas Gildea for their generous assistance in running this study.
In place of two-factor theory, Brosgole (1976b) proposed that RI and PI emerge when materials that have already been partially mastered are organized for storage in memory. It was argued that when two sets of similar materials are related to each other in such a way as to give rise to a sense of "before and after" or "this follows that," the recall of the cognitively prior items (e.g., the stimulus member of a pair) will be at a deficit in short-term memory and the preceptually recent items (e.g., the response member of a pair) will deteriorate in long-term recall. Thus, the phenomena of retroaction and proaction were understood in terms of an organizing principle of cognitive or perceptual primacyrecency.

In the traditional interference design, an original list of items or pairs is followed, upon mastery to a criterion level, by an interpolated list. In this case, temporal order or sequence serves as a powerful organizing principle, grouping the two lists into a perceptually prior one and a recent one. The following study represents an attempt to offset the grouping of temporal sequence by manipulating list content. It was hoped that by varying the context within which the lists were presented, the temporally recent list would have been sensed as preceding the veridically prior one. Thus, the temporal and cognitive determinants of retroaction and proaction were thrown into conflict, using a standard interference procedure.

\section{METHOD}

Rationale

The aim of this study was to assess RI and PI in an instance in which the cognitive-sequential organization of two sets of materials conflicted with their temporal order of presentation. In order to accomplish this, two lists of 12 color/nonsense syllable pairs were integrally embedded within the context of two 
separate stories that denoted events that were connected sequentially within the conditioning history of the subjects. The first story described the excitement associated with Christmas Eve, and the second one told of the jubilance of a New Year's Eve party.

The subjects were presented both stories and were required to learn the embedded color-syllable pairs to a partial criterion level. Both stories contained the same stimuli (colors), which were paired with different response items (syllables). Thus, an A-B,A-C paradigm was used. The second story was presented only after the first one was mastered, so that this was not a simultaneous learning situation. Both sets of materials were relearned $20 \mathrm{~min}$ and $24 \mathrm{~h}$ after the completion of the second story. This enabled us to assess both retroaction and proaction.

The pool of subjects was divided into two equally sized groups. The first group (Group 1) received the Christmas Eve story followed by the New Year's story. For this group, the cognitive organization of the materials was established firmly by an agreement between the context of the stories and their temporal order of presentation. There could have been no doubt as to which story came first and which came last. The order of the two stories was reversed for the second group (Group 2). This treatment was designed to upset the subjects' cognitive structure by creating a disagreement between temporal grouping and experimental organization. In this case, it was reasoned that a confusion might have emerged as to which story came first (perhaps the Christmas Eve story, which was presented last) and as to which was learned second (perhaps the New Year's Eve story, which was mastered first). It was speculated that the conflict between context and temporal order might have given rise to offsetting effects, resulting in an inability to differentiate between the remote and more recent materials and a dissipation of RI and PI.

In summary, it was argued that RI and PI are dependent upon a clear sense of primacy and recency. While this sense is normally generated perceptually by separating lists in time, it may be affected by other factors, such as context. It followed logically that the perception of sequence could be diminished by creating a conflict between temporal order and context, resulting in a reduction of $\mathrm{RI}$ and PI.

\section{Subjects}

Eight males and 11 females participated in this study. They ranged in age from 17 to 23 years, with a mean age of 21.62 years. All were naive as to the purpose of the experiment.

\section{Apparatus and Materials}

Two stories were constructed, one about Christmas Eve and the other about New Year's Eve. Within each of the stories were 12 color/CVC trigram pairs. Both stories contained the same 12 colors, which appeared in different order. These color names were paired with a separate set of CVC trigrams in each story. The trigrams were of $50 \%$ frequency value, according to the Archer (1960) list. The stories were approximately of equal word length (each was 16 lines long) and were presented line by line on a Lafayette memory drum (Model 303). Each story began with the word "start," which was centered in bold type. The following was the Christmas Eve story: "Bursting with excitement, I swiftly raced down the stairs and past the blue wez to see what Santa had delivered the night before. When I entered the room I was captured by the splendor of the Christmas tree, ornamented with a silver yek and colored lights. I gazed at the beautifully decorated presents and the pink zys which surrounded the magnificent tree. To the right of the tree stood a stunning red fup. To the left of the tree was a small lavender beh. The tree itself was garnished with a green mib and a yellow tiv. Underneath the tree was a white juf which was surrounded by a black noj. Two small packages hung from the base of the tree: one was an orange gax while the other was a gold vyt. I was hoping that this Christmas I would get a brown siw." The following passage was used to convey a story about a New Year's Eve party: "I strolled past the pink yun and into the party room filled with friends and relatives to partake in the New Year celebration. I was enchanted with the jubilant mood of the guests who were all standing around the blue jyz. I watched the host who was preparing the silver ruw for everyone. Next to the white gok stood my uncle who was wearing an orange huc. All of the guests were patiently waiting for the brown vad. Looking into the black seb was my little cousin who was wearing a green byl. Two of my close friends stood near the ball which would drop at midnight. One was holding a yellow waj while the other was holding a red zir. I know that they were both hoping for a lavender cef in the coming year. My New Year's resolution was to go out and buy a gold kex."

The method of cued or aided recall was used during learning and delayed recall, with the color names constituting the test stimuli. These test stimuli were presented on another Lafayette memory drum (Model 303).

\section{List Construction}

Each of the two stories may be said to contain a list consisting of 12 paired associates. An attempt was made to insure that the two lists were of comparable difficulty. To this end, each of the lists was presented to a separate group of eight subjects, who had to learn it to full criterion. The two groups were matched for learning ability, in terms of the number of errors and trials required to reach full criterion on a prior paired associate list. All subjects learned the same matching list, which consisted of 12 pairings of color names and two-digit numbers. The list that was ultimately embedded within the Christmas Eve story was learned in a mean of 10.5 trials, with 11.13 errors. The other list was learned in an average of 10.0 trials, with 11.63 errors. Subsequent analyses showed that the two lists were learned in an equivalent number of trials, with a like number of errors. Therefore, the lists contained within the two stories were considered to be of equal difficulty.

\section{Groups}

The subject pool was divided into two groups of equal size. Group 1 was required to learn the Christmas Eve story followed by the New Year's Eve story, and Group 2 learned the stories in the reverse order. Subjects were randomly assigned to either Group 1 or Group 2.

\section{Procedure}

The subjects were informed that this was a two-part experiment attempting to assess the way children remember words and that it was necessary to gather normative data using an older population. The subjects were told that in the first experimental session they would be presented stories that included nonsense words similar to those found in the well known Dr. Seuss children's stories and that in the second session they would be tested on meaningful material. This subterfuge was implemented in order to prevent rehearsal prior to the 24-h test of recall. The actual purpose of the study was disclosed at the conclusion of the second experimental session.

Subjects from both groups were tested for recall after each trial on their respective first story. The story was presented line by line at a 4-sec rate with no delay between lines, with the subjects instructed to read the story aloud upon each presentation. In addition, the subjects were informed that after each trial they would be presented a list of the 12 colors taken from the story and that their task was to name aloud the nonsense word that went with each of the colors. Thus, the method of cued or aided recall was used in which the color names were presented at a 2 -sec rate with no interstimulus interval. These test stimuli were presented in six different orders, which were varied over trials. The trials continued until a partial criterion of 8-10 correct responses was achieved.

Each group was given its respective second story immedi- 
ately afterward. The same procedure was used as in the previous task. After a criterion of 8-10 correct responses was achieved, the subjects were allowed a 20 -min break. They were then presented each of the 12 color names, 1 by 1 , and were required to give the associated nonsense words from both of the stories, with no time restrictions placed on the task. The subjects returned $24 \mathrm{~h}$ later, and the same test of delayed recall was repeated. Thus, each group was tested for recall after $20 \mathrm{~min}$ and after $24 \mathrm{~h}$.

\section{RESULTS AND DISCUSSION}

Group 1 learned the Christmas Eve story followed by the New Year's Eve story. This group recalled an average of 8.7 items on the last trial of original learning, compared to 4.4 items after a 20 -min delay and 5.4 responses $24 \mathrm{~h}$ later. With regard to their second (interpolated) story, Group 1 remembered an average of 9.0 responses on the last learning trial, 9.4 after a 20 -min delay, and 7.2 after a 24-h interval. As can be seen, the originally learned material was markedly forgotten in short-term memory (only $50.6 \%$ retention) and improved in long. term recall (where there was $62.1 \%$ retention). The opposite occurred with the interpolated material, for which there was an increment in short-term memory (104.4\% retention) and a decrement in long-term recall (80.0\% retention). This difference in the recall of original and interpolated learning suggested the presence of retroaction and proaction effects.

Similar effects were observed in Group 2, which learned the New Year's Eve story followed by the Christmas Eve story. For this group, an average of 9.2 correct responses were given on the last trial of original learning, compared to 7.1 after a 20 -min delay and 7.0 items $24 \mathrm{~h}$ later. With regard to the interpolated story, 9.1 items were remembered correctly on the last learning trial, 8.5 were remembered $20 \mathrm{~min}$ later, and 7.8 were recalled after a 24 -h interval. It is apparent that in short-term memory, the recall of the interpolated material $(93.4 \%)$ was superior to that of the originally learned responses $(77.2 \%)$. This superiority diminished in long-term memory, in which $85.7 \%$ of the interpolated responses were recalled and $76.1 \%$ of the originally learned responses were retained. It must be noted that there was no improvement in the memory of the originally learned material from $20 \mathrm{~min}$ to $24 \mathrm{~h}$ and that the recall of the interpolated responses deteriorated progressively as a function time. Therefore, the influence of RI and PI on the recall of this second group was diminished with regard to the effects observed in Group 1. These descriptive data were confirmed by statistical analyses.

The number of correct responses given was subjected to a 2 by 2 by 3 split-plot factorial analysis of variance, using a square-root transformation to correct for small frequencies. There were two within-subjects factors, namely, story (first and second learned, regardless of content) and time (last learning trial and 20-min and 24-h delays). Group ( 1 and 2 ) was the sole between- subjects factor. The analysis revealed a significant threeway interaction among group, story, and time $[\mathrm{F}(2,36)$ $=21.91, \mathrm{p}<.01]$. This interaction was evaluated further by use of simple effects and Newman-Keuls tests.

Simple effects showed that Group 1 significantly forgot both stories as a function of time $(p<.01$ in each case). Newman-Keuls tests indicated that the first story (pertaining to Christmas Eve) was reliably forgotten at $20 \mathrm{~min}(\mathrm{p}<.01)$, with no substantive change thereafter. With regard to the second story (New Year's Eve), there was no difference in recall between the last learning trial and the 20-min interval. However, there was a significant deterioration in retention from $20 \mathrm{~min}$ to $24 \mathrm{~h}(\mathrm{p}<.01)$. Additionally, simple effects indicated that the two stories were recalled equivalently on the last learning trial, but the second story was retained significantly better at the two subsequent delay intervals ( $p<.01$ for each comparison). This interaction between story and time suggests the strong presence of $\mathrm{RI}$ and PI.

In a similar fashion, the simple effects showed that Group 2 also forgot a significant amount of material from both stories over time ( $p<.01$ in each case). Newman-Keuls tests indicated that the first story (regarding New Year's Eve) was forgotten reliably at $20 \mathrm{~min}$ $(p<.01)$, with no further change thereafter. The recall of the second story (relating to Christmas Eve) failed to change from the last learning trial to $20 \mathrm{~min}$ and from the 20-min to the 24-h interval. However, significantly less material was remembered after a 24-h delay, compared to the last trial of learning $(p<.01)$. As for the previous group, simple effects were used to compare the degree to which the two stories were retained. Just as before, it was found that the stories were recalled equivalently on the last learning trial and the second story was remembered significantly better than the first at both delay intervals $(p<.01$ for each comparison). This interaction of Story by Time suggests that RI and PI again emerged, despite the reversal of the context of the two stories. From this, it would be tempting to conclude that temporal sequence is the sole determinant of retroaction and proaction. However, the question may be raised as to whether these sources of interference affected both groups in equal measure. The resolution of this issue resided in a comparison of the two groups.

Simple effects were used to compare Groups 1 and 2 in the recall of the first story learned at each of the three time intervals. While the groups failed to differ on the last trial of original learning, Group 2 retained significantly more responses at both delay intervals $(p<.01$ for each comparison). Thus, it would appear that retroaction was heightened when the order established by the context of the stories was in agreement with the temporal sequence of presentation. To put it conversely, RI was offset significantly when contextual sequence conflicted with temporal order. Disappointingly, this was not found with regard to the second story, which was recalled to a like extent by the two groups at every 
time interval. Thus, the groups were found to differ with regard to retroaction, but not proaction. Perhaps the failure to find a diminished proactive effect in Group 2 can be understood in terms of some other data.

The number of errors to criterion on each of the stories was evaluated for both groups. Group 1 made an average of 27.8 errors in learning the first story (about Christmas Eve) and 30.2 errors in learning the second one. Group 2 committed a mean of 29.6 errors in mastering its first story (about New Year's Eve) and 43.5 errors in learning the second one. From this, it is apparent that the first task produced negative transfer or generated associative interference in the performance of the second task. These data were subjected to a 2 by 2 split-plot factorial analysis of variance, using a square-root transformation to correct for small frequencies. Story (i.e., first and second, regardless of content) served as a withinsubjects factor, and group (1 and 2 ) was a betweensubjects factor. The analysis produced a significant twoway interaction between story and group $[\mathrm{F}(1,18)=$ $9.88, \mathrm{p}<.01]$.

Subsequent simple effects indicated that the two groups committed a like number of errors in learning the first list that was presented, implying that they were matched in terms of learning ability. However, Group 2 made significantly more errors than Group 1 on the second story $[F(1,36)=19.65, p<.01]$. Additionally, Group 1 made essentially the same number of errors in learning both stories, whereas Group 2 committed significantly more errors in reaching criterion on the second task than on the first $[\mathrm{F}(1,18)=31.54, \mathrm{p}<.01]$. Apparently, the negative transfer at the point of interpolation was sufficient to offset a practice effect in Group 1, resulting in a lack of a difference between the errors made to the two stories. However, the conflict generated in the second group by reversing the contextual sequence of the stories generated an enormous amount of associative interference.

A heightened RI effect might have been expected for Group 2, based upon the significant amount of associative interference observed during interpolated learning. Yet, this group manifested a lesser amount than did the other. Perhaps the intrusion of the first story upon the learning of the second had a negative impact upon the delayed recall of the responses from the second story. That is to say, the apparent proaction observed in Group 2 may have been the spurious outcome of the difficulty encountered in mastering the second task.

There is one more piece of evidence supporting the contention that the two groups differed in terms of the degree of retroaction. With regard to Group 1, every single subject retained the responses associated with the first story from $20 \mathrm{~min}$ to $24 \mathrm{~h}$. In fact, the recall of nine of the subjects improved over that interval and the retention of the remaining subject was unchanged. This increment in recall by a significant number of subjects ( $p=.011$ according to the binomial test) seems to reflect the level of spontaneous recovery that should occur hypothetically in instances of RI. In Group 2 , the recall of only three subjects improved from $20 \mathrm{~min}$ to $24 \mathrm{~h}$. The recall of two subjects remained unchanged, and five subjects demonstrated forgetting with the passage of time. The Fisher exact probability test showed that significantly more people forgot the originally learned materials in Group 2 than in Group $1(\mathrm{p}=.025)$.

This is quite opposite to what might have been expected, given the relatively large number of errors committed by Group 2 at the point of interpolation. These errors should have been indicative of the unlearning of the originally learned responses, resulting in a high degree of retroaction and subsequent spontaneous recovery. Yet, it was the first group (and not the second) that demonstrated significantly more retroaction and spontaneous recovery. Perhaps the increment in recall (from short- to long-term memory) that often has been associated with RI is independent of a prior underlying process of unlearning or extinction. As such, the use of the term "spontaneous recovery" would seem to be quite inappropriate in the context of an RI-PI paradigm. For lack of a better term, however, the differential occurrence of apparent spontaneous recovery indicates that interference effects were being assessed by our design and that there was significantly greater retroaction found in Group 1. Therefore, it may be concluded that RI and PI are the result of a sequential structuring of learned materials in memory and that this organization may be determined contextually, as well as temporally.

\section{REFERENCES}

Archer, J. E. A re-evaluation of the meaningfulness of all possible CVC trigrams. Psychological Monographs: General and Applied, 1960, 3(Whole No. 497).

Brosgole, L. Associative symmetry: V. An interference interpretation of the failure of stimulus availability. Bulletin of the Psychonomic Society, 1976, 7, 177-178. (a)

Brosgole, L. Phenomenal determination of retroactive and proactive interference. Psychological Reports, 1976, 38, 1093. 1094. (b)

Brosgole, L., \& Duffy, F. X. The phenomenal determination of retroaction and proaction: II. Evidence of interference during the simultaneous acquisition of two lists. Bulletin of the Psychonomic Society, 1976, 8, 208-210.

Brosgole, L., Lederer, W. G., \& Kozlowski, K. D. The phenomenal determination of retroaction and proaction: $I$. Interference within pairs of a single list. Bulletin of the Psychonomic Society, 1976, 8, 205-207.

(Received for publication November 4, 1982.) 